\title{
¿Intereses económicos en la protesta ambiental? Marcos de interpretación y coaliciones sociales en las movilizaciones ambientales contra sectores extractivos de recursos naturales en Argentina
}

\author{
Gabriela Delamata ${ }^{1}$
}

Recibido: 26-09-2018 / Aceptado: 22-02-2019

Resumen. El trabajo explora cómo se formuló socialmente la cuestión ambiental relacionada con la expansión de sectores extractivos de recursos naturales en Argentina durante las últimas décadas. Para ello analiza los "marcos interpretativos territoriales" de la acción ambientalista en tres sectores y se brinda una explicación basada en las coaliciones sociales de la movilización. El trabajo muestra que la común oposición a las actividades extractivas no se tradujo en una misma formulación del problema, y que la presencia o ausencia de actores económicos capitalizados en la coalición o en el territorio de la movilización ha sido un factor clave en la configuración de distintos marcos de significado.

Palabras clave: cuestión ambiental; sectores extractivos de recursos naturales; marcos interpretativos; coaliciones sociales; Argentina.

\section{[en] Economic interests in environmental protest? Interpretative frames and} social coalitions in the environmental mobilizations against natural resources' extractive sectors in Argentina

\begin{abstract}
This work explores how the environmental issue related to the expansion of natural resources' extractive sectors in Argentina was socially shaped over the last decades. To achieve the objective, it analyzes the "territorial interpretative frames" of environmentalist action in three sectors and provides an explanation based on the social coalitions of the mobilization. The work shows that shared opposition to extractive activities did not translate into a same framing of the issue, and that the presence or absence of capitalized economic actors in the coalition or in the territory of mobilization has been a key factor in the setting of different frames of meaning.
\end{abstract}

Keywords: enviromental issue; natural resources' extractive sectors; interpretative frames; social coalitions; Argentina.

Cómo citar: Delamata, G. (2019): “¿Intereses económicos en la protesta ambiental? Marcos de interpretación y coaliciones sociales en las movilizaciones ambientales contra sectores extractivos de recursos naturales en Argentina”, Política y Sociedad, 56(1), pp. 127-144.

1 Escuela de Política y Gobierno, Universidad Nacional de San Martín, y Consejo Nacional de Investigaciones Científicas y Técnicas (Argentina).

E-mail: gdelamat@unsam.edu.ar 
Sumario. 1. De la negatividad al territorio: marcos y actores de la movilización socioambiental. 2. Sectores extractivos y cuestión ambiental: pregunta, hipótesis, conceptos, método. 3. Los bordes interiores de la protesta ambiental. 4. Marcos de interpretación y coaliciones ambientalistas. 5. Bibliografía.

\section{De la negatividad al territorio: marcos y actores de la movilización socioambiental}

El crecimiento de la protesta ambiental en Argentina está relacionado con la expansión territorial de sectores económicos extractivos de recursos naturales a gran escala, dinamizada por el aumento de la demanda y los precios internacionales de bienes primarios. Durante los últimos años, la localización de megaproyectos de producción de celulosa, la difusión de la gran minería a cielo abierto y la expansión del agronegocio han estado entre los principales blancos de la crítica socioambiental. ${ }^{2}$

Una nota común a la protesta ambiental es el carácter negativo de su posicionamiento público o basado en consignas de oposición. ¡No a las papeleras!, ¡No a la mina!, ¡Paren de fumigar! son máximas que aglutinan la acción ambientalista, expresando antagonismos sociales irreductibles ante el avance de un sector extractivo o hacia alguna de sus externalidades. Frente al rechazo común, han existido, no obstante, distintas maneras de formular el problema ambiental en el territorio o distintos frames territoriales. Estos marcos interpretativos dan contenido específico a lo que se entiende por (derecho al) ambiente, y ponen de manifiesto la existencia de una variedad de intereses entre los afectados por el avance de uno u otro emprendimiento.

Uno de los frames más recurrentes es el que alinea el resguardo del ambiente con la defensa social del modelo productivo local. Como podrá observarse más adelante, este marco fue elaborado en respuesta a la instalación de fábricas de celulosa en la vera oriental del río Uruguay, por habitantes de la ciudad argentinoentrerriana de Gualeguaychú, primer conflicto socioambiental de gran resonancia pública, y es el marco construido en algunas movilizaciones sociales por el control de los recursos naturales y el territorio frente al avance de las explotaciones minero-metalíferas. Un segundo marco hace referencia a la vulneración de derechos humanos fundamentales en la interpretación del asunto ambiental. Lejos

\footnotetext{
En la clasificación utilizada por el Instituto Nacional de Estadísticas y Censos (INDEC), se ubica a estas actividades dentro del sector primario de la economía, distinto del sector industrial y del sector de los servicios. Según Gudynas (2009), la producción foresto-celulósica, la gran minería y el monocultivo agrícola comparten las características de los sectores extractivos en sentido amplio: remueven grandes volúmenes de recursos naturales, los recursos no son procesados o lo son limitadamente, y pasan a ser exportados (Gudynas, 2009: 188-192). Para el autor y otros autores, se trata de figuras emblemáticas del "neoextractivismo", entendido este como un estilo de desarrollo basado en la sobreexplotación de la naturaleza y que genera efectos desestructurantes e impactos negativos en los territorios y las comunidades (Gudynas, 2009; Svampa, 2013; Svampa y Viale, 2014). Cabe mencionar, asimismo, que debido a los insumos y tecnologías que intervienen en el proceso económico, estas actividades suelen ser catalogadas como industriales. En suma, dependiendo de la característica de la actividad en la que se ponga énfasis, cambia el rótulo. El caso más representativo en Argentina es sin dudas el monocultivo de soja, que, como se verá en este trabajo, es considerado uno de los pilares del complejo agroindustrial, o de la "agricultura "moderna" — diferenciándola de la agricultura tradicional o familiar-, y es su vez caratulado como agronegocio, cuando lo que se apunta a señalar es la apuesta al rendimiento económico de la actividad, sin vinculación directa con las necesidades de la población.
} 
de equiparar el (derecho) ambiente con un todo socioproductivo "viable", este marco reclama el cumplimiento de normas que protejan ambientalmente a la población. El marco es claro en el caso de la protesta contra la aplicación de herbicidas químicos en el agro, pero también es observable en el framing de algunas movilizaciones regionales contra la minería.

En la literatura sobre conflictos ambientales, resulta habitual conceptualizar los conflictos por el acceso y el control de los recursos naturales, en términos de distintos ambientalismos o distintas relaciones de definición entre ambiente, sociedad y economía junto con los poderes que los actores sociales esgrimen para ejercer control sobre el ambiente o el territorio (Bebbington y Bebbington, 2009). Aunque el concepto de marco ambiental no es idéntico ${ }^{3}$, partimos de la distinción que Bebbington y Bebbington realizan en el citado artículo entre distintos ambientalismos - como modo de avanzar en una clasificación de los conflictos socioambientales con la minería en Perú, identificando referentes empíricos específicos-, para incorporar nuevos referentes a sus categorías, basados en evidencia del caso argentino, y para comenzar a trazar así la relación entre actores y marcos de la movilización ambiental.

Entre la variedad de ambientalismos descriptos por Bebbington y Bebbington ${ }^{4}$, algunos resultan más permeables a la negociación con el capital transnacional (minero) mientras que otros se oponen a cualquier tipo de transacción. Los primeros incorporan una valorización económica a las valoraciones extraeconómicas de los recursos naturales, mientras que los segundos solo consideran las valoraciones extraeconómicas. La opción que pretendemos agregar y para la cual no habría un "casillero" dentro de la clasificación propuesta por Bebbington y Bebbington es la de los ambientalismos de oposición que incluyen como parte de la coalición a los capitales económicos domésticos. En la literatura sobre conflictos socioambientales, los ambientalismos de oposición tienen como referentes habituales a los actores de subsistencia o a los grupos históricamente excluidos. Mientras que el ecologismo de los medios de vida, conceptualizado por Martínez Alier como ecologismo de los pobres (2011), se ocupa principalmente de los primeros ${ }^{5}$, el ambientalismo denominado de la "justicia socioambiental" apunta fundamentalmente a los segundos. ${ }^{6}$

El punto es que una aproximación a las luchas socioambientales en Argentina no podría obviar no solamente la presencia importante de clases medias en las movilizaciones (Reboratti, 2007: 139; Svampa, Bottaro y Sola Álvarez, 2009: 45), sino también, en particular, la participación de actores económicos capitalizados en

\footnotetext{
Se define "marco ambiental" en la próxima sección.

4 Los ambientalismos descriptos son cinco: conservacionismo, ambientalismo nacionalista-populista, ecologismo de los medios de vida, justicia socioambiental y ecologismo profundo.

5 El ecologismo de los medios de vida es definido por Bebbington y Bebbington como "un ambientalismo que se preocupa por la calidad de, y la accesibilidad a, aquellos recursos naturales que sostienen los medios de vida de distintos sectores de la población” (Bebbington y Bebbington, 2009: 121). Según Martínez Altier, "el eje principal de esta corriente [el ecologismo de los pobres] no es una reverencia sagrada a la naturaleza sino un interés material por el medio ambiente como fuente y condición para el sustento; no tanto una preocupación por los derechos de las demás especies y las generaciones futuras humanas sino por los humanos pobres de hoy" (Martínez Alier, 2011: 34).

6 El ambientalismo "que podría denominarse justicia socio-ambiental [...] parte de una noción de inequidad en la relación entre sociedad y medio ambiente, y una crítica al modelo económico que discrimina o castiga a ciertos grupos de la sociedad [...] maneja un cierto concepto de derechos inalienables y justicia social [...] Insiste en la justicia social para los individuos, sobre todo los históricamente excluidos (Bebbington y Bebbington, 2009: 121).
} 
la protesta ambiental. Como podrá observarse en el análisis de casos, mientras que en algunas movilizaciones los pequeños productores y agentes productivos poco capitalizados son preponderantes, en otras movilizaciones es notable la presencia de actores económicos pertenecientes a sectores de la economía que registraron una fuerte expansión durante la década de 2000, como la agroindustria y el turismo, ambos destacados por su papel en la reactivación económica que experimentó el país por esos años (Fraga, cit. en Hernández, 2009: 39).

Bajo el término agroindustria se engloban distintas actividades agrícolas que atravesaron a partir de 1990 un proceso de reconversión tecnológicoorganizacional, incremento de las inversiones extranjeras y reorientación exportadora, produciendo modificaciones en la estructura socioproductiva, con ganadores (nuevos perfiles empresariales), perdedores (crisis de los pequeños productores) y una nueva trama social agraria: surgimiento de actividades asociadas, encadenamiento con otros sectores y en la dimensión campo-ciudad. Estas transformaciones afectaron de lleno a la vitivinicultura en la provincia de Mendoza, y a la agricultura pampeana, en provincias como Buenos Aires, Córdoba y Santa Fe, facilitando la aparición de nuevas solidaridades sociales alrededor de las reconvertidas economías regionales (Chazarreta, 2014 y 2014; Gras y Hernández, 2009 y 2010; Hernández, 2009; Barsky y Dávila, 2008).

En otras regiones del país, los cambios en el sistema productivo se tradujeron en la modernización parcial de un sector preexistente, como sucedió en el sector de la vitivinicultura y la olivicultura en San Juan y La Rioja (Giarraca y Hadad, 2009), y en el sector productor de frutas, en zonas tradicionalmente dedicadas a ese cultivo, como el alto valle de río Negro (Bendini y otros, 2009). En otros casos, como la provincia de Entre Ríos, se produjo una diversificación de la estructura económica previa, que incorporó a su matriz agrícola-ganadera históricamente poco competitiva (Berhend y Bianchi, 2017), la producción de specialities, como el cultivo del arándano (Craviotti, 2009), y la producción de commodities, la plantación extensiva de soja para exportación.

En síntesis, la oposición entre actores territoriales locales (débiles) y actores económicos transnacionales o globales (fuertes), que es característica en buena parte de los conflictos socioambientales suscitados por la expansión de las fronteras extractivas en América Latina (Bebbignton y Bebbington, 2009; Leff, 2009: 22; Santos, 2005), debe ser en nuestro caso matizada o mediada en la dimensión territorial, en función de la participación de actores económicos locales "fuertes", muchos de ellos integrados verticalmente al mercado global de inversión y comercio, en las disputas, o de la redefinición de intereses que los mismos producen en la trama territorial, afectando, como es el caso en los espacios provinciales mencionados, todos ellos epicentros de luchas ambientales, la gramática de los conflictos.

\section{Sectores extractivos y cuestión ambiental: pregunta, hipótesis, conceptos, método}

¿Cómo se formuló socialmente en Argentina la cuestión ambiental relacionada con la expansión de las fronteras extractivas? Para responder a este interrogante nos 
situamos en un espacio social específico, delimitado por la evolución de las movilizaciones ambientalistas opuestas a la megaminería, las pasteras y el agronegocio, en un periodo comprendido entre las primeras manifestaciones de conflicto (2002) y el pasado reciente. Al entender que el sentido de la cuestión ambiental no puede ser definido a priori ni de manera universal para todos los conflictos y que los frames que se movilizan en cada caso amalgaman dimensiones ambientales y otros valores e intereses (Merlinsky, 2013: 41; Azuela y Mussetta, 2009; Leff, 2006), nuestro objetivo es identificar los frames que cristalizaron durante el ciclo de protesta ${ }^{7}$, y explorar regularidades entre los frames y las coaliciones que han sido sostén de las movilizaciones, como modo de responder a la pregunta planteada.

Concentrado en los marcos y los actores de la movilización social, el trabajo no rastrea todas las posiciones del conflicto, aunque deja sentado el interés de los actores empresariales y los actores estatales que promueven los emprendimientos, en la minimización de los riesgos ambientales. En rigor, las coaliciones socioambientales también están, por su parte, atravesadas por coaliciones sociedadEstado más o menos extensas. Sin embargo, la medida en que los actores políticos participan en las coaliciones depende de las características socioeconómicas de la coalición.

La hipótesis que presentamos es que los actores económicos locales han sido centrales en la formación de coaliciones ambientales y en la configuración del marco ambiental. Mediante su capacidad relativa de agregar intereses en territorio, los actores económicos locales han afectado la extensión de las demandas y el frame de la cuestión ambiental.

El concepto de marco que manejamos posee, retomando la acepción clásica de Benford y Snow $^{8}$, una dimensión expresiva y una dimensión estratégica u orientada al control y la legitimación, por lo cual el marco ambiental es socialmente enunciado como derecho al ambiente. De este modo, distintos frames son distintas maneras de reivindicar valores socioambientales, al revestir con cierta legitimidad a las demandas.

Un marco, en la literatura de movimientos sociales, es una articulación entre dos tipos de componentes (dimensiones): los valores que sostiene o promueve el grupo que se moviliza y los valores, símbolos o normas con los cuales dicho grupo proyecta la legitimidad de sus reclamos o quejas. Ambos componentes aparecerán estratégicamente articulados en una misma argumentación, y es posible que uno tienda a prevalecer sobre el otro, dependiendo de si se trata de reforzar la cohesión del grupo, ampliar adherentes, presentar la justeza de las demandas, etc. Sin embargo, el punto de alineamiento es indecidible en abstracto. Como explica Tarrow, "los impulsores del movimiento orientan el marco de sus movimientos hacia la acción en determinados contextos y le dan forma en la intersección

\footnotetext{
El periodo que abordamos se extiende hasta 2017 , y la elección de esa fecha no obedece sino al momento en que finalizaba nuestra investigación de campo. De forma que no hay allí un "fin de ciclo" de la protesta ambiental surgida a comienzos del siglo. De lo que se trata es de saber si la evolución de las movilizaciones ha ido de la mano de la generación de marcos de significado que, por su extensión, persistencia u otros, pueden asociarse al periodo y considerarse, por lo tanto, estructurantes de un mismo ciclo de protesta (Tarrow, 2004: 207-208; Snow y otros, 1986: 477).

8 Benford y Snow definen marco interpretativo o frame como "el conjunto de significados y creencias orientados a la acción que inspiran y legitiman las actividades y campañas de un movimiento social" (Benford y Snow, 2000: 614; traducción del inglés y subrayado propios).
} 
existente entre la cultura de la población sobre la que trabajan y sus propios valores y fines" (Tarrow, 2004: 160; subrayado propio). Consecuentemente, los marcos ambientales son algo diferente a las formas del ambientalismo. Mientras que el concepto de ambientalismo enfatiza la dimensión antagónica de las movilizaciones ambientales (con las formas económicas y sociales dominantes), el concepto de marco subraya la dimensión hegemónica de las movilizaciones ambientales, enlazando valoraciones del ambiente y producción de legitimidad y reconocimiento en una sociedad y cultura dadas (Tarrow, 2004: 36-37; Snow y otros, 1986: 469).

A fin de identificar y analizar marcos y actores, en la próxima sección resumimos, en un registro descriptivo-evolutivo, las movilizaciones ambientalistas registradas en tres sectores extractivos de recursos naturales en el periodo mencionado, reparando en las estrategias discursivas y en la composición de las coaliciones de la movilización. En la sección siguiente destacamos las regularidades observadas y construimos una tipología de coaliciones que nos permitirá desarrollar la hipótesis, conectando los tipos de marcos con los tipos de coaliciones.

La evidencia recabada para este trabajo proviene de investigaciones desarrolladas por otros autores e investigaciones propias ${ }^{9}$. En relación con la casuística, para el caso "papeleras", relacionado con la localización de plantas de fabricación de celulosa (pasteras) sobre el río Uruguay, retomamos las deliberaciones y actores en la escala territorial o local, a fin de reconstruir el marco ambiental y la integración de la coalición ${ }^{10}$. En el caso de las movilizaciones contra la minería a cielo abierto, ofrecemos un panorama general y analizamos casos que presentan contrastes en la trama productiva provincial, y que nos permiten testear la relación entre marcos y coaliciones ${ }^{11}$. En cuanto a las movilizaciones contra el uso de agroquímicos, describimos el marco ambiental junto a las estrategias de intervención de los afectados dentro del cuadro más amplio de problemáticas y expectativas sociales suscitadas por el agronegocio.

\footnotetext{
En Delamata (diversos años) analizamos diversos aspectos de las movilizaciones ambientales relacionadas con pasteras y megaminería a lo largo de los años. Utilizamos para este artículo parte de la información allí recabada sobre procesos, actores y lenguajes de la movilización ambiental y que fue obtenida en el trabajo de campo mediante el empleo de técnicas cualitativas. En total, se realizaron unas 100 entrevistas a miembros de asambleas ambientales, productores locales, funcionarios del poder ejecutivo municipal y provincial, legisladores provinciales, abogados, ONG, expertos y académicos, en la ciudad de Gualeguaychú (20062007), en distintas localidades de las provincias de Mendoza (2007-2008), La Rioja (2008) y Córdoba (2012) y en la Capital Federal (diferentes momentos). Asimismo, se revelaron y analizaron documentos oficiales y materiales de difusión, se realizaron distintos tipos de observación, no participante y participante, en reuniones de asambleas ambientales, y otras se efectuó un seguimiento del desarrollo de las luchas ambientales a través de páginas web, prensa y redes sociales, y también se obtuvieron y sistematizaron datos estadísticos sobre distintos aspectos de los espacios territoriales estudiados, etc.

10 Como será mencionado, el caso repercutió en otras escalas y arenas de conflicto. Varios estudios han profundizado en las distintas escalas y arenas: Palermo y Reboratti, 2007; Alcañiz y Gutiérrez, 2009; Merlinsky, 2009 y 2013; Delamata, 2009.

11 Para un recorrido bastante exhaustivo sobre los conflictos producidos en todo el país, véase Svampa, Sola Álvarez y Bottaro, 2009. Sobre los debates en materia de ambiente y desarrollo sustentable durante la movilización social y legal en las provincias de Mendoza, Córdoba y Río Negro, puede consultarse nuestro trabajo (2013).
} 


\section{Los bordes interiores de la protesta ambiental}

\section{1.¡No a las papeleras! Sí al modelo socioproductivo proyectado para la región}

Durante la década de 2000, Uruguay puso en marcha políticas de inversión extranjera en el sector foresto-celulósico sobre la cuenca del río Uruguay (Alvarado, 2007), una región compartida con Argentina a través de ese curso de agua. Pese a que la industria celulósica no había registrado signos de conflictividad social en territorio argentino hasta entonces, la toma de conocimiento acerca de la instalación de mega plantas de producción de celulosa sobre la vera oriental del río Uruguay, a cargo de las empresas española ENCE y finlandesa BOTNIA, puso en vilo a los habitantes de una porción de la costa argentina y suscitó el primer conflicto con contenido ambiental de gran resonancia pública en el país. Los habitantes de la ciudad de Gualeguaychú, provincia de Entre Ríos, se opusieron frontalmente al desembarco de las "papeleras" sobre el río compartido, entendiendo que representaba una amenaza a su estilo de desarrollo territorial.

Iniciado en 2002, el conflicto por las pasteras atravesó distintas etapas e instancias, con un fuerte y largo componente de acción directa, hasta convertirse en un litigio judicial entre Argentina y Uruguay, y posteriormente en una sentencia del Tribunal Internacional de la Haya. La decisión judicial no objetó la localización de la pastera BOTNIA, como lo esperaba Gualeguaychú (y que anteriormente había logrado la relocalización de ENCE), sino que impuso a ambos países la obligación de monitorear conjuntamente el funcionamiento de la planta y el manejo de los efluentes.

Para los habitantes de Gualeguaychú, la instalación de fábricas de celulosa de gran volumen frente a las costas de su ciudad amenazaba con ocasionar problemas de contaminación biofísica, pero sus impactos se cualificaban al ser proyectados sobre las características que, a juicio de la asamblea ambiental, dotan a la ciudad y su entorno de un "perfil social y económico" propio: desde el cuidado brindado al medioambiente y a la salud de la población, pasando por el valor paisajístico atribuido al río Uruguay, el desarrollo turístico de la ciudad y alrededores, el valor inmobiliario del suelo, el valor de la producción agrícola (soja, maíz, trigo, girasol, lino, sorgo, arroz, horticultura-floricultura y forrajes) y de la explotación animal (ganado vacuno, producción láctea, apícola y piscicultura), y el valor del comercio y de actividades industriales como la agroalimentaria, según se plasma en el Informe Técnico de la Asamblea Ciudadana Ambiental de Gualeguaychú dado a conocer en julio de $2007^{12}$. En función de los múltiples riesgos, los perjuicios eran "caratulados de catastróficos para Gualeguaychú y sus alrededores", equiparándose el ¡No a las papeleras! con la defensa indeclinable del modelo socioproductivo local. En un volante utilizado para la difusión pública, la Asamblea Ciudadana Ambiental de Gualeguaychú afirmaba:

Gualeguaychú no le otorgó ni le otorgará la licencia social a Botnia. Licencia social es el derecho que deben tener los habitantes a aceptar o no la instalación de

12 Informe difundido semanalmente en el suplemento "Claves" del diario local El Día. 
industrias que modifican compulsivamente el modelo social y económico proyectado para la región.

Los gualeguaychuenses movilizaban una identidad territorial como vecinos de una localidad de reconocido atractivo turístico, sede de los nacionalmente famosos Carnavales de Gualeguaychú, rodeada de espacios naturales para la recreación, los deportes acuáticos y el disfrute del paisaje, y expresaban, a su vez, el interés de múltiples actores locales en la preservación de un perfil productivo apoyado en el crecimiento y dinamismo de las principales actividades económicas de la localidad y la región, el agro y el turismo. La Asamblea Ciudadana Ambiental de Gualeguaychú estaba conformada tanto por ciudadanos de la localidad como por autoridades de los poderes ejecutivo y legislativo municipales, y contaba entre sus miembros más activos a empresarios del turismo y la industria, productores agropecuarios, comerciantes y también representantes de organizaciones sectoriales de primer y segundo grado, como la Corporación del Desarrollo, promotora de las firmas industriales y comerciales de la ciudad, y la Federación Agraria, representativa de los productores agropecuarios a nivel regional.

\section{2. ¡No a la mina! Sí a la economía regional / Sí a la garantía de derechos fundamentales}

Argentina no es considerada un país minero, dado los escasos antecedentes que registró la actividad hasta la década de 1990. Durante esos años se pusieron en funcionamiento los primeros megaemprendimientos minero-metalíferos, con la metodología de cielo abierto, a cargo de empresas trasnacionales, y en la década de 2000 se registró un boom de inversiones extranjeras en actividades de exploración a lo largo de la región andina y preandina. Entre 1990 y 2008, las inversiones en el sector se incrementaron de los 10 millones de dólares a los 2.212 millones de dólares, y la actividad minera pasó de representar un $0,22 \%$ del Producto Bruto Interno al 4\% del PBI (Secretaría de Minería de la Nación, 2009).

En 2002 se originaron las primeras protestas sociales contra la localización de proyectos mineros en la provincia de Chubut, zona patagónica, y las mismas se extendieron hacia el norte y centro del país durante los años subsiguientes, abarcando la casi totalidad de las provincias con potencial minero. Aunque el alcance socioterritorial de las protestas, excepto en el caso de Mendoza, lejos estuvo de adquirir dimensiones provinciales, las provincias devinieron un ámbito institucional privilegiado para las controversias sobre ambiente y minería, dado que son los Gobiernos de ese nivel los encargados de conceder derechos de exploración y explotación minera, así como de legislar y ejecutar políticas ambientales en el espacio de sus jurisdicciones. En tal sentido, son varios los estados provinciales que, con argumentos ambientales, llegaron a prohibir por ley la actividad minera, poniendo en jaque las inversiones en el sector y paralizando el desarrollo de la gran minería en el ámbito de sus jurisdicciones (Chubut, Mendoza, La Pampa, Tucumán, Córdoba, San Luis, Tierra el Fuego). Algunas provincias revisaron sus políticas, y derogaron normas de prohibición anteriormente sancionadas (Río Negro y La Rioja), mientras que otras, finalmente, profundizaron la política nacional de inversiones mineras, facilitando la radicación y la explotación minera 
en sus distritos (Catamarca, San Juan, Santa Cruz, Neuquén, Salta y Jujuy) (Mangini, 2015; Christel, 2015).

El desarrollo de la minería a gran escala se basa en la utilización intensiva de recursos como el agua, la tierra y la electricidad, lo que implica alteraciones morfológicas y ambientales. Un denominador común a las protestas antimineras ha sido el resguardo del agua para el consumo humano y el abastecimiento de actividades económicas y productivas. Dentro de esta base compartida, es posible identificar dos marcos interpretativos entre los elaborados por los actores sociales movilizados contra la minería.

El primero de ellos reposa en la defensa de la economía regional. Esta construcción del asunto ambiental ha estado presente, particularmente, dentro de las provincias de Mendoza y Córdoba, donde el resguardo de las fuentes hídricas y el territorio del avance de la minería se orientó a la protección de actividades productivas del ámbito local: la vitivinicultura y la producción agropecuaria en Mendoza, el turismo, centralmente, en la provincia de Córdoba. En ambas provincias, la acción ambientalista estuvo apoyada en coaliciones sociales amplias, incluyendo asambleas de vecinos, actores económicos y funcionarios políticos municipales (concejales, intendentes) y provinciales (legisladores). En relación con los actores económicos en particular, productores y empresarios vitivinícolas y agrícolas, agentes comerciales y operadores turísticos nucleados en "multisectoriales" locales (Multisectorial del Sur de San Rafael, Multisectorial de General Alvear) fueron todos protagónicos de la movilización ambiental en Mendoza. La Sociedad Rural de San Carlos, que agrupa a productores agropecuarios, fue a su vez pionera de la protesta, mediante la conformación de la primera plataforma de oposición al desarrollo de la minería, el Frente Diamante, en el valle de Uco (Delamata, 2009a y 2013), región donde cobra mayor impulso la vitivinicultura capital-intensiva (Martín y Wagner, 2013). En la provincia de Córdoba, los operadores turísticos y las inmobiliarias de uso residencial disputaron a la minería la ocupación y apropiación de recursos en las sierras y valles donde se concentran la actividad turística y el desarrollo inmobiliario de la provincia (Ferrero et al., 2012).

La vitivinicultura en Mendoza y el turismo en Córdoba cuentan entre las principales actividades económicas de esas provincias y poseen una tradición local (Richard-Jorba, 2008). En los marcos ambientales, se reivindican las actividades productivas, y se identifica el crecimiento económico, la inclusión social y la sustentabilidad ambiental con un estilo de vida digna, una idiosincrasia de raíces remotas y una aspiración hacia el futuro. Esta fórmula, junto a la exigencia de un rol central para las instituciones locales y las instancias participativas en las decisiones sobre el desarrollo, es ilustrada en la siguiente alocución de un representante del poder legislativo de la provincia de Mendoza, pronunciada en ocasión del debate parlamentario que conduciría a la sanción de una ley que suspendió la actividad minera en la provincia (ley 7627/06), antecedente de la norma que finalmente la prohibió.

Tenemos una postura clara de responsabilidad, vamos a seguir en la defensa de todo un estilo de vida, bregando por la defensa del turismo, de toda la producción que nos ha dado de comer, lo que le ha permitido al comercio desarrollarse y que 
todas esas comunidades vayan creciendo a través de los tiempos. En el tratamiento de este tema de la minería tenemos que ser sumamente prudentes, estar alertas de todo un proceso de normas medio ambientalistas que citan para proteger una minería que no sea contaminante y para ello también vamos a exigir que, más allá de la actitud provincial que se tome en el tema del Desarrollo Minero Provincial, que todos los emprendimientos mineros que se asienten tienen que tener la participación del Consejo Deliberante local, de la Audiencia Pública y la votación de los dos tercios de sus miembros, de otra manera no vamos a permitir la explotación minera en ninguna forma. Queremos seguir cultivando nuestros valores y desarrollando una agricultura sustentable en el tiempo que nos permita vivir como hemos vivido hasta ahora, sin contaminación, con dignidad y con superación. ${ }^{13}$

El segundo marco interpretativo presente en la protesta antiminera reivindica el acceso al agua y las actividades económicas de subsistencia, como medios y modo de vida de la población local. Pasible de ser clasificada dentro del "ecologismo de los medios de vida" (Bebbington y Bebbington, 2009; ver nota 4), esta reivindicación es simultáneamente reformulada en términos de derechos humanos vulnerados, dando lugar a una preponderancia de la acción social contenciosa, directa e institucional (litigios judiciales), para la defensa de derechos institucionalmente comprometidos.

Las coaliciones de la protesta reúnen aquí a organizaciones de vecinos, políticos contrarios a los emprendimientos y pequeños actores económicos, principalmente productores agrícolas y/o ganaderos de subsistencia o de baja escala productiva. Distintas circunstancias permiten entender el protagonismo de los pequeños productores en la protesta, puntualmente en la región noroeste del país, allí donde la minería transnacional se consolidó como primer sector económico del distrito, arrojando a los productores locales a una posición aún más débil y con escaso acceso a recursos naturales "limpios" (Machado Aráoz, 2009) (provincias de Catamarca y San Juan) y/o donde los productores de subsistencia no son acompañados en sus reclamos por los productores capitalizados del sector, como ha sido el caso dentro del complejo vitivinícola en San Juan ${ }^{14}$ y vitivinícola y olivícola en La Rioja (Giarraca y Hadad, 2009). Así, el protagonismo de los productores chicos no responde solamente a la prevalencia del grupo de pequeños productores más pobres en esta región del país (Chazarreta \& Rosati, 2016: 100), sino también a las dificultades que encuentran los agricultores de subsistencia para forjar alianzas con los sectores de la agroindustria y, más en general, para extender sus reclamos al conjunto de la sociedad (Christel, 2015).

Esta segmentación de intereses económicos y sociales coloca a los actores del reclamo ambiental en la situación de minorías intensas, y la apelación al marco jurídico para la representación de sus demandas se vuelve más inmediata o más urgente (Cf. Smulovitz, 2008). Tal pasaje puede apreciarse en el siguiente comunicado del 8 de marzo de 2008 de las asambleas riojanas, aunadas bajo el lema "Podemos vivir sin oro, no podemos vivir sin agua", donde se denuncia a los gobernantes,

13 Diputado Julio Simón (Unión Cívica Radical), Diario de Sesiones de la Honorable Cámara de Diputados de la provincia de Mendoza, 13-12-2006.

14 Entrevista a funcionario técnico del INTA San Juan, 07-09-2017. 
... que no tienen escrúpulos [...] para enajenar los bienes comunes poniendo en riesgo la vida de los pobladores y las economías locales como medios de subsistencia y verdadero desarrollo para las comunidades... y el sistemático empobrecimiento del pueblo, vaciando y desresponsabilizando al Estado de sus funciones básicas de garantizar los derechos constitucionales a un ambiente sano...

\section{3.jParen de fumigar! En defensa del derecho a la salud}

La gran expansión de la agricultura en Argentina vino de la mano de la introducción del denominado paquete tecnológico "semilla transgénica, herbicida total (glifosato) y siembra directa", en la tradicional región pampeana y de la ampliación de los cultivos hacia áreas extrapampeanas en el norte del país. En 2009, la superficie dedicada al cultivo de soja transgénica correspondía a más de la mitad de la tierra afectada a la agricultura (18 millones de hectáreas), y el volumen de producción representaba más del $20 \%$ de la producción mundial de soja $(52,6$ millones de toneladas). Ligado a ello, creció la utilización de agroquímicos para fumigar los cultivos, que llegó a los 313 millones de litros en 2010, de los cuales 200 millones corresponden al glifosato (64\%), el herbicida más utilizado en la soja transgénica (Skill y Grinberg, 2013).

La agricultura moderna o paradigma del agronegocio, así llamado por su desvinculación de las necesidades alimentarias y focalización en el incremento de los volúmenes exportables, viene suscitando conflictos sociales por la tierra en el norte del país, a raíz del desplazamiento de comunidades indígenas y campesinas que impulsa la expansión extrapampaeana de la frontera agraria, y conflictos por la salud y el ambiente en los contornos urbanos, como consecuencia de las fumigaciones que se realizan junto a áreas pobladas. Como señalan Domínguez y Sabatino (2005), la percepción de la contaminación es compartida por campesinos organizados y habitantes de las ciudades, y es entendida como violación de derechos. No obstante, mientras que la elaboración del problema entre los campesinos organizados está mediada por un posicionamiento político que juzga incompatibles la agricultura transgénica y la agricultura campesina, la protesta de la población urbana "queda en la denuncia de los responsables y en la exigencia de que se cumplan las normas" (Domínguez y Sabatino, 2005: 5).

En las periferias urbanas priman una "ambientalización" de las problemáticas ligadas a la agricultura moderna, con especial énfasis en los aspectos sanitarios, y un formato de acción de los afectados basado en la demanda a los poderes públicos para que se regule la aplicación de "agrotóxicos", creando áreas de exclusión en los contornos poblados (Barsky et al., 2016).

Esta construcción del asunto y puntualización de las demandas en medidas regulatorias es común a las protestas tanto originadas en centros urbanos que mantienen fuertes vínculos con el agronegocio, como en ciudades que no mantienen relaciones económicas con la actividad. Sin embargo, es en estos últimos casos donde más se ha avanzado en el alcance de las medidas regulatorias exigidas, abarcando la demanda de prohibición de las fumigaciones aéreas. 
En la región pampeana, zona núcleo de la producción transgénica y sojera, los centros urbanos se caracterizan por mantener fuertes vínculos con el agronegocio, en tanto primer sector productivo regional. Allí existe una amplia participación de actores económicos locales en las explotaciones (productores, arrendadores o "rentistas", contratistas), y la actividad es una potente dinamizadora de otro tipo de actividades, comerciales, financieras, de infraestructura urbana, así como de la generación de empleos. Pese a que las transformaciones tecnológicas y organizativas introducidas en las últimas décadas alteraron completamente el perfil anterior del sistema productivo, subsiste, en gran parte de esta región, una conexión imaginaria entre la agricultura tradicional y la agricultura moderna que forja una representación de unidad.

En otras zonas, una rápida expansión del monocultivo durante los últimos años ha impactado sobre poblaciones urbanas que no mantienen relaciones directas con el negocio. En este tipo de espacios se gestaron los casos más renombrados de lucha social contra la aplicación de agroquímicos, sea por el impacto político de la lucha (la condena judicial a los responsables por contaminar) y/o por el creciente protagonismo de los médicos en el estudio y la difusión de la problemática. Equipos de salud pertenecientes a las universidades nacionales de las provincias de Córdoba y Santa Fe desarrollaron una metodología de trabajo para el relevamiento de las situaciones sanitarias locales, consistente en recabar y acumular información periódica sobre los efectos del uso de plaguicidas en la salud humana y su evolución en el tiempo, conocida como "campamentos sanitarios" o "epidemiología comunitaria". Por otro lado, los mismos equipos dieron nacimiento a una red que articula las voces de los profesionales de la salud y la de los afectados, denominada Red de Médicos de Pueblos Fumigados, cuyas declaraciones y reclamos a las autoridades para la regulación del uso de agroquímicos se difundieron en sucesivos encuentros de la red (Barri, 2010) ${ }^{15}$.

15 Extracto de la Declaración del Segundo Encuentro de la Red de Médicos de Pueblos Fumigados (Rosario, 29 de abril de 2011).

"Los miembros de los equipos de salud de los Pueblos Fumigados de la Argentina, junto con científicos, investigadores y académicos, reunidos en la Facultad de Ciencias Médicas de la Universidad Nacional de Rosario, reiteramos nuestras certezas expresadas en la Declaración del Encuentro anterior de agosto de 2010, en la Facultad de Ciencias Médicas de la UN Córdoba. Esto es:

Que es muy importante la agresión a la salud en las poblaciones de localidades sometidas a fumigaciones constantes en la Argentina, y que la situación se agrava días a día, detectándose con mucha mayor frecuencia enfermedades severas como cánceres, abortos espontáneos, trastornos de la fertilidad y nacimientos de hijos con malformaciones congénitas.

[...] Nosotros proponemos como respuesta urgente a este problema que, se PROHIBAN las fumigaciones aéreas en todo el territorio nacional, como ya se estableció en la Unión Europea, y se restrinjan las fumigaciones terrestres alejándolas del límite de las plantas urbanos de los pueblos.

[...] Por otro lado, reclamamos que se reclasifiquen los agrotóxicos considerando sus efectos agudos, de mediano y largo plazo en ensayos de laboratorio y en estudio en humanos. Exigimos que una dependencia de Salud y Ambiente sea la encargada de autorizar o rechazar el uso de cada pesticida en particular, como ocurre como ser en Canadá y no un ente donde solo participan el área de agricultura del Estado, los productores y las Cámaras productivas y comerciales de esos actores.

Por último, queremos reconocer el esfuerzo de todos los miembros de los equipos de salud en general, los vecinos de los pueblos y todos quienes entienden que en esta democracia necesitamos que se prioricen valores, como la salud y el ambiente, sobre los intereses económicos y comerciales de grandes grupos, empresas y pooles de siembra". Disponible en:

$\mathrm{http} / /$ reduas.com.ar/declaracion-del-2-encuentro-de-medicos-de-pueblos-fumigados/

[Consulta: 21 de septiembre de 2018] 
En suma, la agricultura moderna es socialmente legitimada por los beneficios directos e indirectos que reporta, y es a la vez severamente objetada por otra serie de efectos, como degradación de los suelos, deforestación, contaminación del agua, destrucción de la biodiversidad, expulsión de las comunidades rurales (Skill y Grinberg, 2013; Gras y Hernández, 2009). Entre ambos extremos, las luchas urbanas, de corte sanitario y legal-regulatorio, contra el uso de glifosato y otros herbicidas de alta toxicidad, suelen ser catalogadas como protestas y demandas (solo) contra alguna de las externalidades del agronegocio (Cáceres, 2014).

\section{Marcos de interpretación y coaliciones ambientalistas}

En las movilizaciones descriptas identificamos dos marcos de interpretación ambiental que atraviesan las luchas sectoriales: la reivindicación de un modelo productivo local, presente en la protesta contra las pasteras y en una serie de movilizaciones contra la gran minería, y la referencia a derechos humanos vulnerados junto a la exigencia de cumplimiento de normas, ostensible en otro conjunto de movilizaciones contra la minería y en las luchas sociosanitarias contra el agronegocio.

Postulamos que los distintos marcos pueden ser asociados con distintos tipos de coaliciones ambientalistas. La noción de coalición subraya dos componentes de la acción: la diversidad de actores y el objetivo común (McCammon \& Moon, 2015: 326), de modo que las coaliciones ambientalistas pueden ser entendidas como conjuntos de distintos grupos sociales (distintos intereses, agendas, etc.) que comparten un objetivo: hacer cesar el peligro ambiental. Llamamos al primer tipo "coaliciones socioeconómicas". Estas se caracterizan por tener como parte de la coalición a la élite económica local. Al segundo tipo lo llamamos "coaliciones sociales", y el mismo comprende dos conjuntos de coaliciones empíricas: aquellas donde los actores económicos de subsistencia o pequeños productores son preponderantes, por un lado, y las coaliciones sociosanitarias, en las cuales la categoría actor económico no es significativa dentro de la coalición, por el otro. Definimos a la élite económica local como el actor o conjunto de actores (en una economía diversificada) de arraigo territorial, que comanda los sectores económicos de mayor peso $\mathrm{y}$ dinamismo en un espacio socioproductivo determinado.

En base a las regularidades observadas en la sección anterior, postulamos que

1) Existe correspondencia entre los marcos ambientales que reposan en la defensa de un modelo productivo territorial y la existencia de una coalición socioeconómica en la protesta.

2) Existe correspondencia entre los marcos ambientales que reclaman el cumplimiento de los derechos positivos de ambiente y la presencia de una coalición social en la protesta.

3) La presencia de una élite económica local en el territorio de la protesta afecta el marco de la protesta: a) contribuyendo a su formulación, cuando es parte de la coalición (caso 1); b) condicionando la extensión (o radicalidad) de las demandas ambientales, cuando no es parte de la coalición (caso 2). 
La distinción entre los dos tipos de coaliciones apunta a destacar la mayor o menor capacidad de los actores (económicos) en el territorio, de agregar y enlazar a los suyos otros intereses sociales y económicos, afectando la definición y el alcance de los bienes ambientales amenazados. En tal sentido, contrasta la agregación de intereses que es capaz de producir la élite económica local, con la débil capacidad de enlazar intereses de los productores agropecuarios de subsistencia o tradicionales, y de cara a la puntualización de la problemática agraria en los aspectos sociosanitarios del sistema productivo. Son estas diferencias de "poder coalicional" las que se ponen de manifiesto en la gramática del frame, junto a la fuente del derecho proclamada o reclamada para dar legitimidad a las demandas: alternativamente la voluntad de la mayoría o el constitucionalismo y la ley.

La movilización de Gualeguaychú contra las pasteras y las movilizaciones contra la megaminería en Mendoza y en Córdoba permiten observar la participación de los actores y sectores económicos capitalizados de la trama productiva local o regional, en la conformación de un espacio solidario amplio en defensa del ambiente. Los marcos ambientales articulan allí el resguardo de un modelo económico "viable" con dimensiones ambientales y argumentos idiosincráticos. También articulan perfil productivo y democracia local, por cuanto la contribución de los habitantes a forjar el primero es la fuente proclamada del derecho (colectivo) a decidir sobre el ambiente/desarrollo.

Movilizaciones protagonizadas por productores de subsistencia o poco capitalizados ponen de manifiesto que los intereses del sector no alcanzan a ser vector de agregación de otros intereses económicos, los agroindustriales, y que su capacidad de ampliar el propio espacio solidario es débil. Los bienes del ambiente son reivindicados como medio y modo de vida local, junto con la voluntad de la población de decidir sobre ellos; sin embargo, tales bienes difícilmente pueden defenderse como derecho a la forma de vida tradicional. Los bienes del ambiente se desterritorializan parcialmente para ser reformulados en el paradigma de los derechos humanos, en busca de representación para las demandas sociales.

Finalmente, la movilización contra la fumigación con agroquímicos en las zonas núcleo de producción sojera y de otras variedades ocurre en el mismo espacio social en el que la élite económica local ha conseguido legitimar (relativamente) la agricultura moderna, al superponerse, sin neutralizarse, dos intereses: el interés en el desarrollo productivo y el crecimiento económico y el interés en la salud. La lucha ambiental (también) se orienta a la defensa de derechos humanos; en este caso, la defensa del derecho a la salud, y las demandas se dirigen hacia las instancias institucionales para que se hagan efectivas normas de protección de la población.

¿Cómo se formuló entonces socialmente la cuestión ambiental relacionada con la expansión extractiva en el espacio y tiempo delimitados?

De entrada, la común oposición a las actividades extractivas no se tradujo en una común interpretación del problema. Tampoco cada uno de los sectores "adversarios" per se fue percibido de manera unitaria, puesto que interpretaciones del problema disímiles convivieron al interior de un mismo sector e interpretaciones similares del problema atravesaron más de un sector. Si una aproximación desde los ambientalismos permitiría afirmar que las movilizaciones se reparten entre fórmulas intransigentes y fórmulas (meramente) regulatorias de 
cara a las economías extractivas, un análisis como el ensayado en este trabajo debería poder mostrar que "la cultura de la población sobre la que trabajan", citando nuevamente a Tarrow, puede ser un factor importante en la distribución de las fórmulas sociales del ambiente.

La casuística permite considerar que son las características de los actores económicos territoriales - en función de sus intereses y de la potencialidad de estos de suscitar apoyos, construir alianzas y producir solidaridad - las que han redundado en distintas fórmulas de inscripción del problema ambiental. La dinámica coalicional que los intereses orientados al crecimiento favorece o impone afectó a la extensión de las demandas ambientales y al modo como los actores reivindican el derecho, apelando a la legitimidad social y política de las economías "viables" o esgrimiendo razones de orden público para demandas sin (suficiente) representación bajo los nuevos esquemas productivos.

\section{Bibliografía}

Alcañiz, I. y R. Gutiérrez (2009): "From local protests to the International Court of Justice: forging environmental foreign policy in Argentina", en P. Harris (ed.), Environmental change and foreign policy, New York, Routledge Press.

Alvarado, R. (2007): "Política forestal, plantas de celulosa y debate ambiental. Uruguay tras un nuevo modelo de desarrollo", en V. Palermo y C. Reboratti (comps.), Del otro lado del río. Ambientalismo y política entre uruguayos y argentinos, Buenos Aires, Edhasa.

Azuela, A. y P. Mussetta (2009): “Algo más que ambiente. Conflictos sociales en tres áreas naturales protegidas de México", Revista de ciencias sociales, segunda época 16, pp. 191-215.

Barri, F. R. (2010): "Pueblos fumigados en Argentina: resistencia epidemiológica comunitaria al modelo económico de los agronegocios", Ecología Política 40, pp. 67-72.

Barsky, A., D. Cassano, P. Flores y M. Rivarola (2016): “Conflictos ambientales derivados de la aplicación de agroquímicos por fuentes móviles con impacto en instituciones escolares de la provincia de Buenos Aires", presentado en el Seminario Internacional Conflictos Urbanos y Ambientales, Derecho y Espacio Público, UNGS-UNSAM-UBA, Los Polvorines y Ciudad de Buenos Aires, 27 y 28 de octubre.

Barsky, O. y M. Dávila (2008): La rebelión del campo. Historia del conflicto agrario argentino, Buenos Aires, Sudamericana.

Bebbington, A. y D. H. Bebbington (2009): “Actores y ambientalismos: conflictos socioambientales en Perú", Íconos 35, pp. 117-128.

Bendini, M., M. Murmis y P. Tsakoumagkos (2009): "Pluriactividad: funciones y contextos. Preguntas teóricas y análisis de dos zonas frutícolas del Alto Valle rionegrino", en C. Gras y V. Hernández (coords.), La Argentina rural. De la agricultura familiar a los agronegocios, Buenos Aires, Biblos.

Benford, R. y D. Snow (2000): "Framing processes and social movements. An Overview and Assessment", Annual Review of Sociology, 26, pp. 611-639.

Berhend, J. y M. Bianchi (2017): "Estructura económica y política subnacional en Argentina", Caderno CRH, 30 (80), pp. 217-235. 
Cáceres, D. (2015): “Accumulation by dispossession and socio-environmental conflicts caused by the expansion of agribusiness in Argentina", Journal of Agrarian Change 15 (1), pp.116-147.

Chazarreta, A. (2014): "Recomposición económica de las burguesías regionales: la burguesía vitivinícola en la provincia de Mendoza, Argentina (1990-2011)”, Población \& Sociedad 21 (1), pp. 61-97.

Chazarreta, A. (2014a): "Los cambios en la organización gremial de la burguesía vitivinícola de la provincia de Mendoza, Argentina (1990-2011)", Pampa 10, pp. 55-85.

Chazarreta, A. y G. Rosati (2016): "Los cambios en la estructura social agraria argentina", en G. Kessler (comp.), La sociedad argentina hoy. Radiografia de una nueva estructura, Buenos Aires, Sigloveintiuno.

Christel, L. (2015): Resistencias sociales y legislaciones mineras en las provincias argentinas: los casos de Mendoza, Córdoba, Catamarca y San Juan (2003-2009), Tesis Doctoral, UNSAM.

Craviotti, C. (2009): “Tecnologías intangibles y relaciones interempresariales: los agentes productivos en el cultivo del arándano en Entre Ríos", en C. Gras y V. Hernández (coords.), La Argentina rural. De la agricultura familiar a los agronegocios, Buenos Aires, Biblos.

Delamata, G. (2009): “¿La ciudadanía poblana? El movimiento asambleario de Gualeguaychú y la construcción y el reclamo de un derecho colectivo”, en G. Delamata (coord.), Movilizaciones sociales: ¿nuevas ciudadanías? Reclamos, derechos, Estado en Argentina, Bolivia y Brasil, Buenos Aires, Biblos.

Delamata, G. (2009a): "Las resistencias sociales contra la minería transnacional en Argentina. Una aproximación a la escala provincial en la constitución de nuevas identidades políticas", 21 Congreso Mundial de Ciencia Política (IPSA-AISP), Santiago de Chile, 12-16 de julio. Disponible en:

http://paperroom.ipsa.org/papers/paper_3557_pdf

Delamata, G. (2013): “Actualizando el derecho al ambiente. Movilización social, activismo legal y derecho constitucional al ambiente de sustentabilidad fuerte en el sector extractivista megaminero", Revista de Sociología de la UBA Entramados y Perspectivas 3 (3), pp. 55-90.

Delamata, G. (2017): "Las ciudades como constructoras de causas del medio natural y rural. Activismo ambiental, modelos productivos y ciudadanías en la Argentina contemporánea”, en P. Ramírez Kuri (coord.), La erosión del espacio público en la ciudad neoliberal, Ciudad de México, Universidad Nacional Autónoma de México, Instituto de Investigaciones Sociales.

Domínguez, D. y P. Sabatino (2005): "La muerte que viene del viento. La problemática de la contaminación por efecto de la agricultura transgénica en Argentina y Paraguay", Informe final del concurso CLACSO. Los impactos socioculturales y económicos de la introducción de la agricultura transgénica en América Latina y el Caribe. Disponible en: http://bibliotecavirtual.clacso.org.ar/ar/libros/becas/2005/soje/domsa/pdf

Ferrero, M., G. Ibáñez Mestre y M. Machado Ibars (2012): “A la sombra de un modelo económico: el caso de la minería en Córdoba", en M. A. Ciuffolini (comp.), Por el oro y el moro. Explotación minera y resistencias en Catamarca, Córdoba y La Rioja, Buenos Aires, El Colectivo.

Giarracca, N. y G. Hadad (2009): "Disputas manifiestas y latentes en La Rioja minera. Política de vida y agua en el centro de la escena”, en M. Svampay M. Antonelli (eds.), 
Minería trasnacional, narrativas del desarrollo y resistencias sociales, Buenos Aires, Biblos.

Gras, C. y V. Hernández (2009): "El fenómeno sojero en perspectiva; dimensiones productivas, sociales y simbólicas de la globalización agrorrural en la Argentina", en C. Gras y V. Hernández (coords.), La Argentina rural. De la agricultura familiar a los agronegocios, Buenos Aires, Biblos.

Gras, C. y V. Hernández (2010): "Renta, conocimiento e identidad. El estatus de la tierra en el nuevo modelo y las disputas por sus funciones”, en V. Hernández (comp.), Trabajo, conflictos y dinero en un mundo globalizado, Buenos Aires, Biblos.

Gudynas, E. (2009): "Diez tesis urgentes sobre el nuevo extractivismo", en VVAA, Extractivismo, politica y sociedad, Quito, Centro Andino de Acción Popular y Centro Latino Americano de Ecología Social.

Hernández, V. (2009): "La ruralidad globalizada y el paradigma de los agronegocios en las pampas gringas”, en C. Gras y V. Hernández (coords.), La Argentina rural. De la agricultura familiar a los agronegocios, Buenos Aires, Biblos.

Leff, E. (2006): “La ecología política en América Latina. Un campo en construcción”, en H. Alimonda, Los tormentos de la materia. Aportes para una ecología política latinoamericana, Buenos Aires, CLACSO.

Machado Aráoz, H. (2009): "Minería transnacional, conflictos socioterritoriales y nuevas dinámicas expropiatorias. El caso de Minera Alumbrera", en M. Svampay M. Antonelli (eds.), Minería trasnacional, narrativas del desarrollo y resistencias sociales, Buenos Aires, Biblos.

Mangini, M. (2015): Economía política del cambio institucional en la política minera de las provincias argentinas, Tesis de Maestría, Universidad Torcuato Di Tella.

Martín, F. \& L. Wagner (2013): “Agua o minería. Determinaciones y movilizaciones en la construcción del conflicto ambiental en Mendoza”, en G. Merlinsky (comp.), Cartografías del conflicto ambiental en Argentina, Buenos Aires, Ciccus.

Martínez Alier, Joan (2011): El ecologismo de los pobres. Conflictos ambientales y lenguajes de valoración, Barcelona, Icaria.

Maccammon, H. y M. Moon (2015): “Social movement coalitions”, en D. Della Porta y M. Diani, Handbook of Social Movements, Oxford, Oxford University Press.

Merlinsky, G. (2009): Atravesando el río: la construcción social y política de la cuestión ambiental en Argentina, Tesis de Doctorado, Universidad de Buenos Aires-Universidad Paris VIII.

Merlinsky, G. (comp.) (2013): Cartografias del conflicto ambiental en Argentina, Buenos Aires, Ciccus.

Palermo, V. y C. Reboratti (comps.) (2007): Del otro lado del río. Ambientalismo y política entre uruguayos y argentinos, Buenos Aires, Edhasa.

Reboratti, C. (2007): “Ambientalismo y conflicto ambiental en el río Uruguay”, en V. Palermo y C. Reboratti (comps.), Del otro lado del río. Ambientalismo y política entre uruguayos y argentinos, Buenos Aires, Edhasa.

Richard-Jorba, R. (2008): "Los empresarios y la construcción de la vitivinicultura capitalista en la provincia de Mendoza (Argentina), 1850-2006”, Scripta Nova, Revista Electrónica de Geografía y Ciencias Sociales XII (271), pp.1-27.

Santos, M (2005): "O retorno do território", OSAL 16, pp.255-258.

Skill, K. y E. Grinberg (2013): "Controversias socio-técnicas en torno a las fumigaciones con glifosato en Argentina. Una mirada desde la construcción social del riesgo”, en G. 
Merlinsky (comp.), Cartografias del conflicto ambiental en Argentina, Buenos Aires, Ciccus.

Snow, D., E. Jr. Burke Rochford, S. Worden y R. Benford (1986): "Frame alignment processes, micromobilization, and movement participation", American Sociological Review 51 (4), pp. 464-481.

Svampa, M., L. Bottaro y M. Sola Álvarez (2009): "La problemática de la minería metalífera a cielo abierto: modelo de desarrollo, territorio y discursos dominantes", en M. Svampa y M. Antonelli (eds.), Minería trasnacional, narrativas del desarrollo y resistencias sociales, Buenos Aires, Biblos.

Svampa, M., M. Sola Álvarez y L. Bottaro (2009): "Los movimientos contra la minería metalífera a cielo abierto: escenarios y conflictos. Entre el 'efecto Esquel' y el 'efecto La Alumbrera'", en M. Svampa y M. Antonelli (eds.), Minería transnacional, narrativas del desarrollo y resistencias sociales, Buenos Aires, Biblos.

Svampa, M. (2013): “'Consenso de los Commodities' y lenguajes de valoración en América Latina", Nueva Sociedad 244, pp. 30-46.

Svampa M. y E. Viale (2014): Maldesarrollo. La Argentina del extractivismo y el despojo, Buenos Aires, katz.

Smulovitz, C. (2008): “La política por otros medios. Judicialización y movilización legal en la Argentina", Desarrollo Económico 48 (189-190), pp. 287-305.

Tarrow, S. (2004): El poder en movimiento. Lo movimientos sociales, la acción colectiva y la política, Madrid, Alianza. 